\title{
Paratesticular Leiomyosarcoma: A Case Report
}

\author{
Vijaya Patil,' Ashish Verma,' Ravindra S. Pattar, 'Sanjay Nandar' \\ 'Department of General Surgery, Sri B. M. Patil Medical College, Hospital \& Research Centre, Bijapur, Karnataka, India.
}

\section{ABSTRACT}

Paratesticularleiomyosarcomas are rare neoplasms. Radical orchidectomy and high ligation of cord followed by surveillance is the treatment of choice. Here we report a 73-year-old man who presented with a 2-year history of painless lump in the left hemiscrotum. A left radical orchiectomy with high ligation of the spermatic cord was performed. The histo-pathological and immunohistochemistry evaluation revealed a moderately differentiated leiomyosarcoma of paratesticular region. The patient is still alive with no evidence of local recurrence and distant metastasis after seven years of follow-up.

Keywords: leiomyosarcoma; spermatic cord; paratesticular; surgical procedures.

\section{INTRODUCTION}

Leiomyosarcoma is malignant soft tissue tumour arising from smooth muscle cells. Ten percent of paratesticular sarcomas are leiomyosarcoma. The tumour usually presents as discrete nodular slow growing painless mass which is separate from testis ${ }^{1}$ in men of middle age or old age often mistaken as benign tumour. ${ }^{2}$ Standard treatment for this tumour consist of radical orchiectomy with high ligation of cord followed by surveillance..$^{1,2}$ However, optimal local and systemic treatment remains controversial. Adjuvant radiotherapy and role of chemotherapy has not been fully established. ${ }^{1}$ Here we report a case of paratesticulartumour of Grade II treated successfully with radical orchidectomy.

\section{CASE REPORT}

A 73-year-old man presented with a 2-year history of painless lump in the left hemiscrotum. He had no history of trauma, sudden increase in size or associated pain. Clinical examination of the scrotum revealed a $5 \times 6 \mathrm{~cm}$, non-tender, firm-to-hard lump at the root of the scrotum separate from the left testis. The lump was not freely mobile \& was attached to the left spermatic cord. Secondary hydrocele present. The routine blood investigations were normal. Ultrasound scan of the scrotum showed normal appearance on the right side, with a distinct and well circumscribed $4 \times 3.2 \times$ $2.5 \mathrm{~cm}$ lesion of mixed heterogeneous echogenicity on the left side. It was abutting the upper pole of the left epididymal head but separate from the epididymis and the testis. The lesion itself showed increased vascularity. Abdominal $\mathrm{CT}$ found to be normal. A left radical orchiectomy with high ligation of the spermatic cord was performed and specimen was formalin-fixed and sent for histo-pathology reporting.

Macroscopy: Specimen of testis with spermatic cord with tumour. Spermatic cord measuring $10 \mathrm{cms}$ in length. Tumour size $5 \times 5 \times 3 \mathrm{cms}$. Testis measuring $4.5 \times 2.5 \times 1 \mathrm{~cm}$. external surface is nodular grey white,

Correspondence: Department of General Surgery, Sri B. M. Patil Medical College, Hospital \& Research Centre, Bijapur, Karnataka, India. Email: drvijayapati@yahoo.com, Phone No: +919916461105. 
firm in consistency. Cut surface show variegated appearance with large area of haemorrhage seen. Multiple lobulated grey white areas seen (Figure 1).

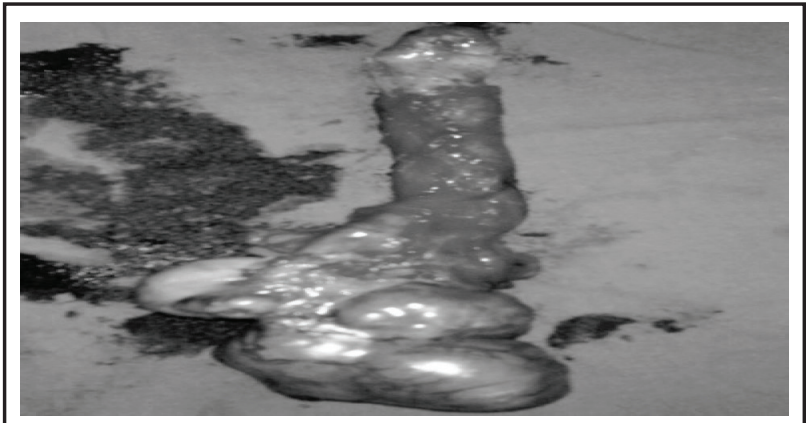

Figure 1. Testis with spermatic cord with tumour.

Microscopy: Microscopic examination revealed cells arranged in well-defined fascicles with central hyperchromatic nuclei and a moderate amount of eosinophilic cytoplasm. There were 8-10 mitoses per 10 high power fields.Figure 2. Small foci of necrosis were noted with the appearances of a spindle cell lesion of probable smooth muscle origin. The high cellularity, pleomorphism, necrosis \& mitotic activity suggested this was a high-grade malignant tumour. Sections studied from testis, epididymis \& spermatic cord show no tumour tissue.

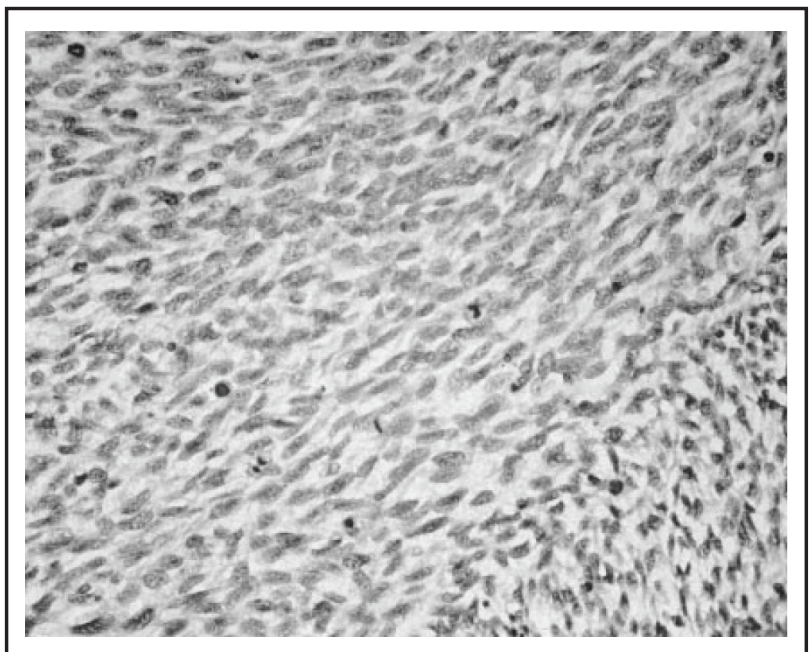

Figure 2. Haematoxylin and eosin stain showing high mitotic index.

Immunohistochemistry: It strongly expressed musclespecific actin, desmin and vimentin. CD68, alpha 1 -antitrypsin, S-100 were negative. Figure 3.

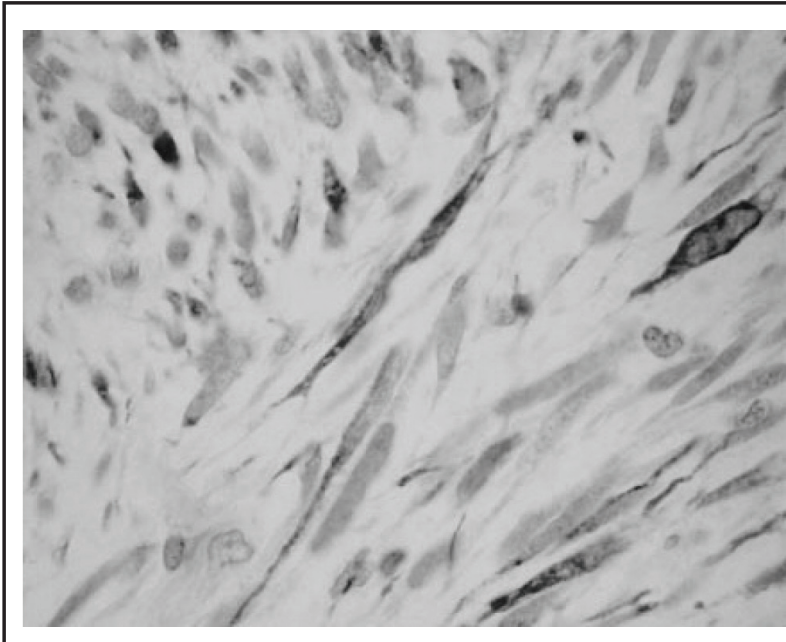

Figure 3. Positive staining with an immunohistochemical marker for smooth muscle (haematoxylin and eosin stain; original magnification, $\times 200$ ).

Data suggested moderately differentiated leiomyosarcoma of paratesticular region, probably arising from the connective tissue.

The patient was clinically, biochemically and radiologically followed-up every 6 months in the first two years and annually thereafter. Tests done were complete hemogram, liver enzymes, a chest $\mathrm{X}$-ray, scrotal ultrasound and $\mathrm{CT}$ abdomen and pelvis. On follow up of seven years there was no clinical or radiological recurrence.

\section{DISCUSSION}

Paratesticularleiomyosarcomasare rare malignant tumour arising from smooth muscle cells of mesenchymal origin from structures around testicle (spermatic cord, epididymis and scrotum).Spermatic cord leiomyosarcomas are rare neoplasias which have been reported in less than 150 cases so far. ${ }^{3}$

This lesion is seen in all age groups. It is mostly diagnosed in the $6^{\text {th }}$ decade. Although etiology remains unclear, some author suggest local irradiation during childhood as potential cause. ${ }^{4}$ The diagnosis is always based on histological examination and immunochemical staining. ${ }^{5}$ Other rare benign tumours like fibrous tumour, leiomyoma, fibro-mesothelioma pseudotumors are its differential diagnosis. ${ }^{6}$ The most common mode of spread is lymphatic to retroperitoneal lymph nodes, followed by haematogenous spread and by local extension to scrotum, inguinal canal along vas deference has been reported. ${ }^{7}$

The standard treatment for all paratesticular sarcomas consist of radical orchidectomy with high ligation of 
cord. ${ }^{1,2}$ The prognosis is usually good without local recurrence or distant metastasis during follow up in Grade I \& II tumours (according to $\mathrm{NCl}$ system) that were treated with only radical orchidectomy. ${ }^{3}$ Role of adjuvant chemotherapy is not clear. Some studies have reported increase in metastasis free survival in patients with $\mathrm{NCl}$ Grade III sarcoma using doxorubicin and ifosfamide based chemotherapy. ${ }^{5}$ Overall survival was $75 \% .^{8}$

Our patient has grade Ilparatesticularleiomyosarcoma. Despite the grade Iltumor, our patient did not develop metastatic or recurrent disease. This indicates that irrespective of the tumor grade, a high inguinal orchiectomy is adequate treatment for these patients.
It also offers further evidence that leiomyosarcoma in this location responds better than at any other site.

In conclusion, paratesticularleiomyosarcoma are rare tumours, treated with radical orchidectomy with high ligation of cord and most of them are low grade tumour with better prognosis. However, long term follow up is necessary to prevent recurrence and distant metastasis.

\section{ACKNOWLEDGEMENTS}

Written consent was obtained from the patient for publication of patient's details.

\section{REFERENCES}

1. Khoubehi B, Mishra V, Ali M, Motiwala H, Karim o. Adult paratesticular tumours. BUJ Int. 2002;90:707-15.

2. Tsai YC, Chung HM, Tzeng KH, Luo FJ. Paratesticularleiomyosarcoma - a case report. JTUA. 2008;19:122-4.

3. Mohammadi TP, Zham H. Epithelioid Type of ParatesticularLeiomyosarcoma: A Case Report and Literature Review. Urology Journal 2004; 1(3):215-17.

4. Dalton DP, Rushovich AM, Victor TA, Larson R. Leiomyosarcoma of the scrotum in a man who had received scrotal irridation as a child. J Urol. 1988;139:136-8.
5. Ko BS, Kim NY, Ryu AJ, Kim DS, Gong SJ, Kim DK, et al. A case of paratesticularleiomyosarcoma successfully treated with orchiectomy and chemotherapy. Cancer Res Treat. 2012;44(3):210-4.

6. Fisher C, Goldblum JR, Epstein JI, Montgomery E. Leiomyosarcoma of the paratesticular region: $\mathrm{s}$ clinicopathologic study. Am J SurgPathol. 2001;25:1143-9.

7. Dangle P, Basavraj DR, Bhattarai S, Paul AB, Biyani CS. Leiomyosarcoma of the spermatic cord: case report and literatutr review. Can UrolAssoc J. 2007;1:55-8.

8. Coleman J, Brennan MF, Alektiar K, Russo P: Adult spermatic cord sarcomas: management and results. Ann SurgOncol. 2003; 10: 669-75. 